\title{
Association of an NFKB1 intron SNP (rs4648068) with gastric cancer patients in the Han Chinese population
}

Renquan $\mathrm{Lu}^{1,2 \dagger}$, Xiang $\mathrm{GaO}^{1 \dagger}$, Yin Chen ${ }^{1}$, Jian $\mathrm{Ni}^{3}$, Yongfu $\mathrm{Yu}^{4}$, Sheng $\mathrm{Li}^{5,6}$ and Lin Guo ${ }^{1,2^{*}}$

\begin{abstract}
Background: Hyperactivation of nuclear factor-KB (NF-KB) is associated with various types of tumors. This study investigated the susceptibility of the rs4648068 A/G genotype in the intron region of NFKB1 to gastric cancer and the association of this polymorphism with clinicopathologic variables in gastric cancer patients.

Methods: A hospital-based case-control study of 248 gastric cancer patients and 192 control individuals was conducted in Fudan University Shanghai Cancer Center (Shanghai, China). Single nucleotide polymorphism (SNP) rs4648068 genotype in NFKB1 from blood samples of a total of 440 people was analyzed by polymerase chain reaction-based genotyping.

Results: The frequencies of the AA, AG, and GG genotypes of the rs 4648068 polymorphism were $31.5 \%, 47.2 \%$, and $21.3 \%$ in the gastric cancer patients and $29.7 \%, 59.9 \%$, and $10.4 \%$ in the control individuals, respectively. We found that the GG genotype was associated with a significantly increased risk of gastric cancer $(P=0.042)$. Furthermore, among the gastric cancer cases, the rs 4648068 GG genotype was associated with high clinical stage (AOR $=2.27,95 \%$

$\mathrm{Cl}$ : 1.11- 4.66), lymph node involvement ( $\mathrm{AOR}=2.90,95 \% \mathrm{Cl}=1.40-6.03)$ and serosa invasion ( $\mathrm{AOR}=2.78,95 \%$

$\mathrm{Cl}=1.34-5.75)$. However, rs4648068 genotypes were not associated with tumor differentiation in gastric cancer patients.
\end{abstract}

Conclusions: Homozygous rs4648068 GG was associated with an increased risk of gastric cancer, especially for the lymph node status and serosa invasion in Han Chinese population.

Keywords: NFKB1, Gastric cancer, Single nucleotide polymorphism (SNP), Susceptibility

\section{Background}

Gastric cancer (GC) is the second leading cause of cancer-related deaths and the fourth most frequent cancer in the world [1]. Generally, GC mortality is ranked the highest in Eastern Asia (China, Japan), Eastern Europe, and South America compared with other cancerous tumors, whereas GC mortality is ranked the lowest in North America and most parts of Africa. The etiology of this cancer is multifactorial, involving both genetic and environmental risk factors. To clarify the genetic background of the gastric cancer, it is necessary to

\footnotetext{
* Correspondence: jykca@sina.com

${ }^{\dagger}$ Equal contributors

'Department of Clinical Laboratory, Shanghai Cancer Center, Fudan

University, Shanghai 200032, China

${ }^{2}$ Department of Oncology, Shanghai Medical College, Fudan University,

Shanghai 200032, China

Full list of author information is available at the end of the article
}

specifically identify the genetic factors such as single nucleotide polymorphisms (SNPs).

Nuclear factor kappa B (NF- $\mathrm{kB}$ ) is a family of structurally related eukaryotic transcription factors that are persistently active in the pathogenesis of numerous malignancies, including prostate [2], breast [3,4], colorectal [5], pancreatic [6], oral [7], and gastric carcinoma cancer [8]. The NF- $\mathrm{kB}$ family contains five members in mammals: NFKB1 encoding p50, NFKB2 encoding p52, $R E L A$ encoding p65, REL encoding c-Rel, and RELB encoding Rel-B. The most common dimer is the p65/p50 heterodimer. The human NFKB1 gene is located at chromosome 4q24. Several groups have shown that there is a relationship between gastric cancer and the polymorphisms of NFKB1 promoter regions $[9,10]$, and local tumor growth and lymph node spread in gastric cancer have also been proven to be associated with $\mathrm{N}$ -

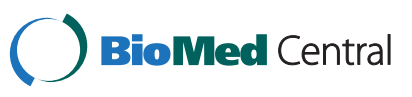

(c) 2012 lu et al.; licensee BioMed Central Ltd. This is an Open Access article distributed under the terms of the Creative Commons Attribution License (http://creativecommons.org/licenses/by/2.0), which permits unrestricted use, distribution, and reproduction in any medium, provided the original work is properly cited. 
myc downstream-regulated genes in previous reports [11-13]. This study investigated the possible association between the SNP polymorphisms of NFKB1 and susceptibility to gastric cancer and its tumor behavior.

We first screened SNPs throughout the entire NFKB1 gene locus and selected 4 SNP sites from 99 SNP sites that were in linkage disequilibrium (LD) in the Hapmap CHB (Han Chinese in Beijing, China) data: rs12509517 and rs4648068, which are in LD with the tagging SNP rs230539 $\left(r^{2}>0.8\right)$, and rs4648065 and rs4648037 $\left(r^{2}<0.8\right)$. The genetic associations of the SNPs were examined by comparing the genotypes of 30 unrelated gastric cancer patients with those of 30 healthy controls in a small-scale genotyping study. Then, we conducted a large-scale case-control study on the Han Chinese population to investigate the association of the rs4648068 polymorphism with gastric cancer and clinicopathologic variables of gastric cancer patients using quantitative real-time PCR (qRT-PCR).

\section{Methods}

Patients and tissue samples

A total of 440 unrelated Chinese participants including 248 patients with gastric cancer and 192 unaffected control participants were recruited with written informed consent, and all human samples were collected with the approval of the Ethics Committee at the Fudan University Cancer Hospital. All subjects were part of the Han population in China. Age, gender, and other clinicopathologic characteristics were evaluated by reviewing medical charts and pathologic records. There were no differences in age and gender between gastric cancer patients and the control participants $(P>0.05)$.

\section{Sample preparation and NFKB1 genotyping}

DNA samples were prepared and genotyped as described previously $[14,15]$. Briefly, genomic DNA was extracted from peripheral blood samples of each study subject using the TIANamp Blood DNA Kit (Tiangen Biotech, China). Four NFKB1 SNPs (rs12509517, rs4648068, rs4648065, rs4648037) were genotyped by SYBR allelic discrimination, and their corresponding qRT-PCR specific primers are listed in Table 1 . PCRs were run in a 20 $\mu \mathrm{L}$ reaction solution containing $30 \mathrm{ng}$ of template DNA and $10 \mu \mathrm{L}$ SYBR Premix Ex Taq (Takara, Japan) according to the manufacturer's instructions. PCR was performed at $95^{\circ} \mathrm{C}$ for $10 \mathrm{~min}$ and 40 cycles at $95^{\circ} \mathrm{C}$ for $30 \mathrm{~s}$ and $58^{\circ} \mathrm{C}$ for $30 \mathrm{~s}$. The samples were amplified, read, and analyzed in Opticon ${ }^{\circledR}$ Fluorescence Temperature Cycler (MJ Research, Canada).

\section{Statistical analysis}

The Haploview 4.2 software (http://www.broad.mit.edu/ mpg) was used to draw a LD map for 99 SNPs (with
Table 1 Primers used for quantitative real-time PCR assays

\begin{tabular}{lll}
\hline SNP & Primer & Primer sequence \\
\hline rs12509517 & Upstream fwd & 5' ACG TAC TAG GAA GTC CTA C 3' \\
& Upstream fmut & 5' ACG TAC TAG GAA GTC CTA G 3' \\
& Downstream rev & 5' GGT TAT GCA GGA TGT TAC CAT TGG 3' \\
rs4648065 & Upstream fwd & 5' TAA CGT ATG CA A CAG GAA C 3' \\
& Upstream fmut & 5' TAA CGT ATG CA A CAG GAA T3' \\
& Downstream rev & 5' GAT ATC TाT CTG CAC CTA GGA CTG3' \\
rs4648068 & Upstream fwd & 5'TAA TTG TTA GAG ATT CCA A 3' \\
& Upstream fmut & 5' TAA TTG TTA GAG ATT CCA G3' \\
& Downstream rev & 5' ACA ATG TTA GAT TाT ACC ATG ATT3' \\
rs4648037 & Upstream fwd & 5' TAA CAC CTT AAA AGG GTG C3' \\
& Upstream fmut & 5' TAA CAC CTT AAA AGG GTG T3' \\
& Downstream rev & 5' ATC ATT TAA TCA GTT GCC ATT GGG3' \\
\hline
\end{tabular}

minor allele frequency $\geq 0.05$ ) located in the NFKB1 region according to the genotype data for Han Chinese populations of the International HapMap Project (HapMap Data Rel 27 Phase II + III, Feb09, on NCBI B36 assembly, dbSNP b126) and to measure the pairwise LD values between SNPs. The SNPs that were tagged by these 4 SNPs with $r^{2}>0.6$ can be illustrated with the LD map [16].

Adjusted odds ratio (AOR) and associated 95\% confidence interval (CI) were calculated using multivariate logistic regression analysis. The comparison of age and gender were performed by student $t$ - test and Pearson chisquare test, respectively, where $P<0.05$ indicated a significant difference. All of the association calculations were conducted with SPSS (version 13.0; SPSS Inc., Chicago).

\section{Results}

Gastric cancer susceptibility association of 4 NFKB1 SNPs

To identify the genetic variations in NFKB1 that are associated with a susceptibility to gastric cancer, we examined the NFKB1 region and selected 4 SNP sites from 99 SNP sites in LD of NFKB1: rs12509517 and rs4648068, which are in LD with the tagging SNP rs230539 $\left(\mathrm{r}^{2}>0.8\right)$, and rs4648065 and rs4648037 $\left(r^{2}<0.8\right)$. According to the genotype data for the $\mathrm{CHB}$ by the International HapMap Project, the values of LD between these 4 SNPs and other ungenotyped polymorphisms in the HapMap database are shown in Additional file: 1 Figure S1, in which rs4648037, rs4648065, rs4648068, and rs12509517 are located at sites $142,168,169$, and 188, respectively. As illustrated in this Additional file: 1 Figure S1, all of the ungenotyped polymorphisms were tagged by these 4 tag SNPs with $r^{2}>0.6$.

A small-scale qRT-PCR genotyping study was conducted to examine the genetic association of these SNPs with gastric cancer. Because polymorphisms in intron or exon regions are all reported to regulate transcription and 
translocation [17-20], we selected 2 intron polymorphisms (rs12509517, rs4648068) and 2 exon SNPs (rs4648065, rs4648037) out of the SNP pool for our analysis.

Comparison of 30 gastric cancer patients and 30 healthy control individuals showed that only SNP rs4648068 had a significant association with susceptibility to gastric cancer $(P=0.029)$, whereas the other 3 SNPs showed no association with susceptibility to gastric cancer (Table 2). Of the individuals with gastric cancer, $33.3 \%$ had the GG genotype in rs4648068, compared with $10 \%$ with the GG genotype in the healthy control individuals. In contrast, the probability of AA alleles in gastric cancer patients is $13.3 \%$ less than that in healthy controls. Surprisingly, this SNP, rs4648068, is in the intron region of the NFKB1 gene. Because there are many previous reports on intronic SNPs that were associated with the activity of protein expression [21], diseases [22], or disorders [23] through gene regulation and transcript processing [24], we conducted a large-scale study of rs4648068.

An NFKB1 polymorphism is associated with an increased risk of gastric cancer

After the preliminary small-scale genotyping, we conducted a large-scale genotyping study of rs4648068. Analysis of the rs4648068 genotype polymorphism showed a

Table 2 Genotype distribution of 4 SNPs in gastric cancer patients and control subjects

\begin{tabular}{cllll}
\hline $\begin{array}{l}\text { Cases } \\
(n=30)\end{array}$ & $\begin{array}{l}\text { Health } \\
\text { Controls } \\
(n=30)\end{array}$ & $\begin{array}{l}\text { AOR } \\
(95 \% \mathrm{Cl})\end{array}$ & $\begin{array}{l}P \\
\text { Value }\end{array}$ \\
\hline $\mathrm{n} \quad \%$ & $\mathrm{n} \quad \%$ & &
\end{tabular}

\begin{tabular}{lllllll} 
rs12509517 & & & & & & \\
GG & 14 & 46.7 & 9 & 30.0 & $1.08(0.53-2.21)$ & 0.601 \\
CG & 12 & 40.0 & 18 & 60.0 & $0.76(0.31-1.63)$ & 0.420 \\
CC & 4 & 13.3 & 3 & 10.0 & 1.00 & \\
rs4648065 & & & & & & \\
TT & 6 & 20.0 & 3 & 10.0 & $1.73(0.83-4.12)$ & 0.313 \\
CT & 8 & 26.7 & 3 & 10.0 & $1.62(0.99-2.69)$ & 0.065 \\
CC & 16 & 53.3 & 24 & 80.0 & 1.00 & \\
rs4648068 & & & & & & \\
GG & 10 & 33.3 & 3 & 10.0 & $2.90(1.01-6.93)$ & $0.029 *$ \\
AG & 16 & 53.4 & 17 & 56.7 & $1.68(0.62-4.01)$ & 0.293 \\
AA & 4 & 13.3 & 10 & 33.3 & 1.00 & \\
rs4648037 & & & & & & \\
TT & 15 & 50.0 & 22 & 73.3 & $0.63(0.28-1.39)$ & 0.193 \\
CT & 8 & 26.7 & 5 & 16.7 & $0.67(0.40-1.83)$ & 0.390 \\
CC & 7 & 23.3 & 3 & 10.0 & 1.00 & \\
\hline AOR, adjusted & & & &
\end{tabular}

$\mathrm{AOR}$, adjusted odds ratio, which was calculated using multivariate logistic regression adjusted by age and gender; $\mathrm{Cl}$, confidence interval.
Table 3 Genotype distribution and allelic frequencies of NFKB1 rs4648068 polymorphism in gastric cancer patients and control subjects

\begin{tabular}{|c|c|c|c|c|}
\hline & Gastric Cancer & Controls & AOR $(95 \% \mathrm{Cl})^{\Delta}$ & $P$ value \\
\hline Cases (n) & 248 & 192 & / & / \\
\hline Age & $57 \pm 11^{*}$ & $53 \pm 15$ & / & / \\
\hline Gender (M/F) & $160 / 88^{* *}$ & $119 / 73$ & / & / \\
\hline \multicolumn{5}{|l|}{ Genotype } \\
\hline $\mathrm{GG}(\%)$ & $53(21.3)^{\#}$ & $20(10.4)$ & $1.92(1.02-3.60)$ & 0.042 \\
\hline$A G(\%)$ & $117(47.2)$ & 115(59.9) & $0.75(0.48-1.16)$ & 0.195 \\
\hline AA (\%) & 78(31.5) & $57(29.7)$ & 1.00 & \\
\hline \multicolumn{5}{|c|}{ Allelic frequencies } \\
\hline $\mathrm{G}(\%)$ & $223(45.0)$ & 155(40.4) & $1.13(0.99-1.36)$ & 0.198 \\
\hline$A(\%)$ & $273(55.0)$ & 229(59.6) & 1.00 & \\
\hline
\end{tabular}

* and ${ }^{*}, P>0.05$ and minor allele frequency $(\mathrm{MAF})=0.346 ; \mathrm{M}$, male; $\mathrm{F}$, female; \#, $P=0.042$ (GG is risk factor); ${ }^{\Delta}$, multivariate logistic regression adjusted by age and gender.

significant difference between gastric cancer patients and control individuals (Table 3). The rs4648068 GG genotype was significantly more common in the gastric cancer patients than in the control individuals $(P=0.042)$, which further implied that homozygous GG was a genetic risk factor for gastric cancer and agreed well with the results of our preliminary small-scale genotyping study described above. Results of stratified analyses by age, clinical stage, tumor differentiation, lymph node status, and serosa invasion with the NFKB1 rs4648068 A/G polymorphism variant genotypes and alleles are presented in Table 4.

\section{Association between NFKB1 rs4648068 polymorphism and age/gender of gastric cancer patients}

The role of the rs4648068 polymorphism in different age groups and gender groups of gastric cancer patients was evaluated. Because age and gender are reported to be the 2 major risk factors of gastric cancer, and this disease is reported to be more common in men over the age of 55 than in other groups [25-28], we divided the gastric cancer patients into 2 age groups (age $\leq 55$ and age $>55$ ), or groups that were divided by gender. However, the associations of this polymorphism with age and gender were not statistically significant.

\section{Association of NFKB1 rs4648068 polymorphism and clinical stage of gastric cancer}

We evaluated whether the association between the rs4648068 polymorphism and gastric cancer was modified by the clinical stages of the cancer by dividing the gastric cancer patients into 2 groups: clinical stages I + II and clinical stages III + IV. The frequency of the GG genotype in clinical stages III + IV was significantly higher than that in clinical stages I + II $(P=0.025, \mathrm{AOR}=$ 
Table 4 Association between the genotype of the NFKB1 rs4648068 polymorphism and patient characteristics

\begin{tabular}{|c|c|c|c|c|c|c|c|c|c|c|c|c|c|}
\hline & $\mathrm{N}$ & GG & AOR $(95 \% \mathrm{Cl})^{\Delta}$ & $P$ value $^{\Delta}$ & GA & $\operatorname{AOR}(95 \% \mathrm{Cl})^{\Delta}$ & $P$ value $^{\Delta}$ & AA & AOR $(95 \% \mathrm{Cl})^{\Delta} P$ value $^{\Delta}$ & G & A & AOR $(95 \% \mathrm{Cl})^{*}$ & $P$ value* \\
\hline \multicolumn{14}{|l|}{ Clinical Stage } \\
\hline$I I I+I V$ & 128 & $33(25.8)$ & $2.27(1.11 \sim 4.66)$ & 0.025 & $62(48.4)$ & $1.55(0.87 \sim 2.78)$ & 0.139 & $33(25.8)$ & - & $128(50.0)$ & $128(50.0)$ & $1.86(1.22 \sim 2.82)$ & 0.004 \\
\hline $1+\|$ & $12020(16.7)$ & - & & & $55(45.8)$ & - & & $45(37.5)$ & - & $95(39.6)$ & $145(60.4)$ & - & \\
\hline \multicolumn{14}{|c|}{ Tumor differentiation } \\
\hline Poor & 118 & $29(24.6)$ & $1.34(0.66-2.70)$ & 0.418 & $52(44.1)$ & $0.89(0.50 \sim 1.58)$ & 0.680 & $37(31.4)$ & - & $110(46.6)$ & $126(53.4)$ & $1.08(0.71 \sim 1.63)$ & 0.729 \\
\hline Well \& moderate & 130 & $24(18.5)$ & - & & $65(50.0)$ & - & & $41(31.5)$ & - & $113(43.5)$ & $147(56.5)$ & - & \\
\hline \multicolumn{14}{|c|}{ Lymph node status } \\
\hline Positive & 111 & $29(26.1)$ & $2.90(1.40 \sim 6.03)$ & 0.004 & $59(53.2)$ & $2.44(1.33-4.50)$ & 0.004 & $23(20.7)$ & - & $117(52.7)$ & 105(47.3) & $2.67(1.72 \sim 4.13)$ & 0.001 \\
\hline Negative & 137 & $24(17.5)$ & - & & $58(42.3)$ & - & & $55(40.1)$ & & 106(38.7) & 168(61.3) & - & \\
\hline \multicolumn{14}{|l|}{ Serosa invasion } \\
\hline Positive & 126 & $34(27.0)$ & $2.78(1.34 \sim 5.75)$ & 0.006 & $62(49.2)$ & $1.74(0.97-3.13)$ & 0.064 & $30(23.8)$ & - & 130(51.6) & $122(48.4)$ & $2.17(1.42 \sim 3.31)$ & 0.001 \\
\hline Negative & 122 & 19(15.6) & - & & $55(45.1)$ & & & $48(39.3)$ & - & $93(38.1)$ & $151(61.9)$ & - & \\
\hline
\end{tabular}

$\triangle$, Multivariate logistic regression adjusted by age and gender (genotype $A A, A O R=1.00) ; ~ *$, multivariate logistic regression adjusted by age and gender $(\mathrm{A}$ carrier, $A O R=1.00)$. 
2.27, 95\% CI: 1.11- 4.66), indicating an association between high clinical stage and the $G$ allele (Table 4).

\section{NFKB1 rs4648068 is associated with the survival of gastric cancer patients}

As indicated in Table 4, lymph node status and serosa invasion were significantly associated with the survival of gastric cancer patients. Stratified analyses by lymph node status showed that patients carrying the $G$ allele were more likely than those carrying the A allele to have a positive lymph node status (52.7\% versus $38.7 \%, P=0.001)$. Furthermore, there was a significant correlation between the genotype and serosa invasion. The frequency of the GG genotype in serosa invasion-positive patients was significantly higher than that in serosa invasion-negative patients $(27.0 \%$ versus $15.6 \%, P=0.006)$. The frequency of $\mathrm{G}$ carriers in serosa invasion-positive patients was also significantly higher than that in serosa invasion-negative patients (51.6\% versus $38.1 \%, P=0.001, \mathrm{AOR}=2.17,95 \%$ CI: 1.42- 3.31). However, rs4648068 genotypes were not associated with the tumor differentiation in gastric cancer patients (Table 4).

\section{Discussion}

NF- $\mathrm{KB}$ was reported to be a proinflammatory transcription factor, which could bind the enhancer of the kappa light chain of immunoglobulin and promote tumorigenesis [29,30]. The rs4648068 $(\mathrm{A}>\mathrm{G})$ polymorphism was identified in a study of the analysis of variation in NFKB1 genes and expression levels of NF- $\mathrm{KB}$ regulated molecules, and SNP rs4648068 was subsequently reported to be associated with VCAM1 and LDL phenotypes [31,32].

Considering there is a relationship between gastric cancer and the promoter region of NFKB1 [9,10] and many reports also showed that the genetic variations in introns might involve alternative gene regulation, transcript processing, or chromosomal rearrangements $[16,17,23,24]$, the association between the rs4648068 polymorphism in NFKB1 and gastric cancer has been studied. Here, we found that the rs4648068 polymorphism had a significantly different distribution in gastric cancer patients and healthy control individuals in a preliminary small-scale genotyping study $(P=0.029)$. Therefore, we investigated the role of the NFKB1 rs4648068 polymorphism in gastric cancer susceptibility in the Han Chinese population in a case-control study. The results indicated that people with the homozygous GG alleles in rs4648068 had a 2.65-fold increased risk of gastric cancer compared people carrying other rs4648068 alleles $(P=0.042)$.

Surprisingly, although reports showed that age and gender are the 2 major risk factors of gastric cancer, and gastric cancer is reported to be more common in men over the age of 55 than in other groups of individuals
[25-28], our stratified analysis by age and gender did not modify the association between rs4648068 and the risk of gastric cancer. Lewander's group [33] and Gao's group [34] have reported that the genetic polymorphisms have the opposite effect in Swedish populations compared with Chinese populations and in Asian populations compared with Caucasian populations. Whether our results are ethnically dependent requires further elucidation. In addition, although the minor allele frequency (MAF) of rs4648068 is high (0.346), this conclusion would be more convincing if it can be replicated in another cohort.

On the basis of our genetic association data in the Han Chinese population, the SNP within an NFKB1 intron region (rs4648068) showed marginal significance. This suggested that there might be correlation between NFKB1 genotypes and the gastric cancer clinicopathologic characteristics such as lymph node status and serosa invasion because of the different associations that were observed for the high-risk subsets and the low-risk subsets.

The SNP rs4648068 (A or G) resides in intron 11 of NFKB1, occupying position 103,518,305 of chromosome 4. The predominant nucleotide at this position is A for human, chimpanzee, and macaque, but $\mathrm{G}$ for orangutan, mouse, and dog. There is no conserved trait at this position in the genome of elephants, opossum, chicken, or zebrafish, although the corresponding region is $\mathrm{Nfkb}$ in these organisms. The percentages of the A and G alleles in the Han Chinese ethic group in Beijing are 0.609 and 0.391 (www.Hapmap.org), respectively; our study in Shanghai found that the percentages of the A and G alleles are 0.551 and 0.449 , respectively. The discrepancy may result from geographic factors because the percentages of A and $\mathrm{G}$ alleles in Han Chinese in Denver, Colorado, are also different from the above findings (A: 0.596; G: 0.404, data from www.Hapmap.org). To elucidate the potential functional role of SNP rs4648068, we also performed a bioinformatic data mining study using the UCSC genome browser (http://genome.ucsc.edu/cgibin/hgTracks) and Encode databases. The region near rs4648068 in intron 11 of NFKB1 exhibited increased levels of H3K9me1 and H3K4me1 (the highest value of $\mathrm{H} 3 \mathrm{~K} 9 \mathrm{me} 1$ is 15 , while the increase of the H3K4me1 level is not as remarkable as that of $\mathrm{H} 3 \mathrm{~K} 9 \mathrm{me} 1)$. These tracks displayed maps of chromatin state that were generated by the Broad/MGH ENCODE group using chromatin immunoprecipitation coupled with sequencing (ChIPseq). Chemical modifications (methylation for H3K9me1 and acetylation for $\mathrm{H} 3 \mathrm{~K} 4 \mathrm{me} 1$ ) to the histone proteins that are present in chromatin influence gene expression by changing the accessibility of the chromatin to transcription factors. The increased levels of chemomodification imply that rs4648408 may be located in a regulatory element, such as an enhancer. Hence, the G 
allele of rs4648068 may alter the power of a potential enhancer, which may have an influence on disease in the host.

In the present study, we observed that the frequency of the G allele in clinical stages III + IV patients was significantly higher than that in clinical stages I+ II patients, indicating that this polymorphism is associated with high clinical stage $(P=0.025)$. On the other hand, the stratified analysis by lymph node status showed that patients with the GG genotype and G carriers were more likely than those with the AA genotype and A carriers to have a positive lymph node status $(P=0.004$ and 0.001 , respectively), suggesting that this polymorphism might contribute to the constitutive NF- $\mathrm{kB}$ activity in gastric cancer.

Our investigations also demonstrated that the frequency of the GG homozygous_genotype in serosa invasion-positive patients was significantly higher than that in serosa invasion-negative patients $(P=0.006)$. Tumor invasion is regulated by numerous NF- $\mathrm{KB}$ target gene products, including MMP-9, TIMP-1/2, PAL 2, CXCR4, interleukin-8 (IL-8), and other chemokines $[29,35,36]$. NF- $\mathrm{KB}$ plays an essential role in the migration and the organ-specific homing of metastatic breast cancer cells $[35,37]$.

\section{Further study}

In our future experiments, we plan to use a dualluciferase reporter assay in gastric cancer cell lines (MKN28, SNU216, SNU16, SCG7901, and HGC-27) to observe the LPS-induced luciferase expression level, which correlates with the mRNA level, to explore whether the mechanism of this association involves alternative gene regulation and transcript processing.

\section{Conclusions}

In this study, we have shown that people who carry the GG homozygous_genotype of the rs4648068 polymorphism in the NFKB1 gene appear to be at increased risk for developing gastric cancer. Furthermore, in gastric cancer patients, the $\mathrm{G}$ allele is associated with high clinical stage, positive lymph node status, and positive serosa invasion.

\section{Additional file}

Additionaf file 1: Figure S1. LD map including 4 SNPS of the NFKB1 genomic region in the Han Chinese population. The rs4648037, rs4648065, rs4648068, and rs12509517 SNPs are located at sites $142,168,169$, and 188, respectively. The values of LD between these 4 SNPS (shown are $r^{2}>0.6$ ) and other ungenotyped polymorphisms are presented.

\section{Competing interests}

The authors have no competing interests to declare.

\section{Acknowledgments}

This research was supported by grants from the National Basic Research Program of China (2010CB933902) and Science and Technology Commission of Shanghai Municipality (074119642). We are deeply grateful to Dr. Megan Hitchins for her enlightening instruction on the bioinformatics in this study.

\section{Author details}

${ }^{1}$ Department of Clinical Laboratory, Shanghai Cancer Center, Fudan University, Shanghai 200032, China. ²Department of Oncology, Shanghai Medical College, Fudan University, Shanghai 200032, China. ${ }^{3}$ Institute of Micro-Nano Science and Technology, Shanghai Jiao Tong University, Shanghai 200240, China. ${ }^{4}$ Department of Biostatistics, School of Public Health, Fudan University, Shanghai 200032, China. ${ }^{5}$ Department of Biochemistry, Dalian Medical University, Shandong 116011, China. ${ }^{6}$ Yulong Biomedical Group, Shanghai 200233, China.

\section{Author contributions}

$\mathrm{RQL}$ designed the study and analyzed and interpreted the data. XG participated in clinical data and information collection. YC and SHL collected all samples and performed qRT-PCR genotyping experiments. YFY and JN were involved in statistical analysis of the data and drafted and edited the manuscript. LG conceived and supervised the project and reviewed the manuscript. All authors have read and approved the final manuscript.

Received: 9 November 2011 Accepted: 10 July 2012

Published: 10 July 2012

\section{References}

1. Jemal A, Bray F, Center MM, Ferlay J, Ward E, Forman D: Global cancer statistics. CA Cancer J Clin 2011, 61:69-90.

2. Chen CD, Sawyers CL: NF-kappa B activates prostate-specific antigen expression and is upregulated in androgen-independent prostate cancer. Mol Cell Biol 2002, 22:2862-2870.

3. Tai DI, Tsai SL, Chang YH, Huang SN, Chen TC, Chang KS, Liaw YF: Constitutive activation of nuclear factor kappaB in hepatocellular carcinoma. Cancer 2000, 89:2274-2281.

4. Biswas DK, Dai SC, Cruz A, Weiser B, Graner E, Pardee AB: The nuclear factor kappa B (NF-kappa B): a potential therapeutic target for estrogen receptor negative breast cancers. Proc Natl Acad Sci U S A 2001, 98:10386-10391.

5. Lind DS, Hochwald SN, Malaty J, Rekkas S, Hebig P, Mishra G, Moldawer LL, Copeland EM 3rd, Mackay S: Nuclear factor-kappa B is upregulated in colorectal cancer. Surgery 2001, 130:363-369.

6. Wang W, Abbruzzese JL, Evans DB, Chiao PJ: Overexpression of urokinase-type plasminogen activator in pancreatic adenocarcinoma is regulated by constitutively activated RelA. Oncogene 1999, 18:4554-4563.

7. Rueda B, Nunez C, Lopez-Nevot MA, Paz Ruiz M, Urcelay E, De la Concha EG, Martin J: Functional polymorphism of the NFKB1 gene promoter is not relevant in predisposition to celiac disease. Scand J Gastroenterol 2006, 41:420-423.

8. Uranishi H, Tetsuka T, Yamashita M, Asamitsu K, Shimizu M, Itoh M, Okamoto T: Involvement of the pro-oncoprotein TLS (translocated in liposarcoma) in nuclear factor-kappa B p65-mediated transcription as a coactivator. J Biol Chem 2001, 276:13395-13401.

9. Kim JG, Sohn SK, Chae YS, Moon JH, Kim SN, Kang BW, Kim GC, Lee MH Jeon SW, Chung HY, Yu W: No association of the NFKB1 insertion/deletion promoter polymorphism with survival in patients with gastric cancer. Jpn J Clin Oncol 2009, 39:497-501.

10. Lo SS, Chen JH, Wu CW, Lui WY: Functional polymorphism of NFKB1 promoter may correlate to the susceptibility of gastric cancer in aged patients. Surgery 2009, 145:280-285.

11. Tchernitsa O, Kasajima A, Schafer R, Kuban RJ, Ungethum U, Gyorffy B, Neumann U, Simon E, Weichert W, Ebert MP, Rocken C: Systematic evaluation of the miRNA-ome and its downstream effects on mRNA expression identifies gastric cancer progression. J Pathol 2010, 222:310-319.

12. Inagaki $Y$, Tang $W, X u H L$, Guo Q, Mafune K, Konishi T, Nakata M, Sugawara $\mathrm{Y}$, Kokudo N: Localization of N-myc downstream-regulated gene 1 in gastric cancer tissue. Dig Liver Dis 2009, 41:96-103.

13. Akiyama $Y$, Watkins $N$, Suzuki $H$, Jair KW, van Engeland $M$, Esteller $M$, Sakai H, Ren CY, Yuasa Y, Herman JG, Baylin SB: GATA-4 and GATA-5 transcription factor genes and potential downstream antitumor target 
genes are epigenetically silenced in colorectal and gastric cancer. Mol Cell Biol 2003, 23:8429-8439.

14. Wang S, Tian L, Zeng Z, Zhang M, Wu K, Chen M, Fan D, Hu P, Sung JJ, Yu J: IkappaBalpha polymorphism at promoter region (rs2233408) influences the susceptibility of gastric cancer in Chinese. BMC Gastroenterol 2010, 10:15.

15. Ju H, Lim B, Kim M, Kim YS, Kim WH, Ihm C, Noh SM, Han DS, Yu HJ, Choi BY, Kang C: A regulatory polymorphism at position -309 in PTPRCAP is associated with susceptibility to diffuse-type gastric cancer and gene expression. Neoplasia 2009, 11:1340-1347.

16. Carlson CS, Eberle MA, Rieder MJ, Yi Q, Kruglyak L, Nickerson DA: Selecting a maximally informative set of singlenucleotide polymorphisms for association analyses using linkage disequilibrium. Am J Hum Genet 2004, 74:106-120.

17. Sjakste T, Paramonova N, Grislis Z, Trapina I, Kairisa D: Analysis of the single-nucleotide polymorphism in the $5^{\prime} \cup T R$ and part of intron I of the sheep MSTN gene. DNA Cell Biol 2011, 30:433-444.

18. Zhu $L B, X u Q$, Hong $C Y$, Yue $Z$, Zhang $Y$, Ye HN, Yuan $Y$ : XPC gene intron $11 \mathrm{C} / \mathrm{A}$ polymorphism is a predictive biomarker for the sensitivity to NP chemotherapy in patients with non-small cell lung cancer. Anticancer Drugs 2010, 21:669-673.

19. Chen P, Xie $L$, Huang GY, Zhao XQ, Chang C: Mutations of connexin43 in fetuses with congenital heart malformations. Chin Med J (Engl) 2005, 118:971-976.

20. Zhang X, Fu L, Zhang Q, Yan L, Ma Y, Tu B, Liu N, Qiao J: Association of TRB3 Q84R polymorphism with polycystic ovary syndrome in Chinese women. Reprod Biol Endocrinol 2011, 9:46.

21. Elens L, Bouamar R, Hesselink DA, Haufroid V, van der Heiden IP, van Gelder T, van Schaik RH: A New Functional CYP3A4 Intron 6 Polymorphism Significantly Affects Tacrolimus Pharmacokinetics in Kidney Transplant Recipients. Clin Chem 2011, 57:1574-1583.

22. Chuo LJ, Wu ST, Chang HI, Kuo YM: Extremely rare incidence of the UBQLN1 polymorphism (UBQ-8i) in Taiwan Chinese with Alzheimer's disease. Neurosci Lett 2010, 475:108-109.

23. Athanasiu L, Mattingsdal M, Melle I, Inderhaug E, Lien T, Agartz I, Lorentzen S, Morken G, Andreassen OA, Djurovic S: Intron 12 in NTRK3 is associated with bipolar disorder. Psychiatry Res 2011, 185:358-362.

24. Weickert CS, Miranda-Angulo AL, Wong J, Perlman WR, Ward SE, Radhakrishna V, Straub RE, Weinberger DR, Kleinman JE: Variants in the estrogen receptor alpha gene and its mRNA contribute to risk for schizophrenia. Hum Mol Genet 2008, 17:2293-2309.

25. Silecchia G, Greco F, Bacci V, Boru C, Pecchia A, Casella G, Rizzello M, Basso $\mathrm{N}$ : Results after laparoscopic adjustable gastric banding in patients over 55 years of age. Obes Surg 2005, 15:351-356.

26. Christie J, Shepherd NA, Codling BW, Valori RM: Gastric cancer below the age of 55: implications for screening patients with uncomplicated dyspepsia. Gut 1997, 41:513-517.

27. Arendt R, Hauzeui F: Relations between age, gastric juice secretion and gastritis. Z Alternsforsch 1973, 27:161-167.

28. Billington BP: Gastric ulcer: age, sex, and a curious retrogression. Australas Ann Med 1960, 9:111-121.

29. Aggarwal BB: Nuclear factor-kappaB: the enemy within. Cancer Cell 2004, 6:203-208.

30. Sen R, Baltimore D: Inducibility of kappa immunoglobulin enhancer-binding protein Nf-kappa B by a posttranslational mechanism. Cell 1986, 47:921-928.

31. Liu-Mares W, Sun Z, Bamlet WR, Atkinson EJ, Fridley BL, Slager SL, de Andrade $\mathrm{M}$, Goode EL: Analysis of variation in NF-kappaB genes and expression levels of NF-kappaB-regulated molecules. BMC Proc 2007, 1(Suppl 1):S126.

32. Kraja AT, Culverhouse R, Daw EW, Wu J, Van Brunt A, Province MA, Borecki IB: The Genetic Analysis Workshop 16 Problem 3: simulation of heritable longitudinal cardiovascular phenotypes based on actual genome-wide single-nucleotide polymorphisms in the Framingham Heart Study. BMC Proc 2009, 3(Suppl 7):S4.

33. Lewander A, Butchi AK, Gao J, He LJ, Lindblom A, Arbman G, Carstensen J, Zhang ZY, Sun XF: Polymorphism in the promoter region of the NFKB1 gene increases the risk of sporadic colorectal cancer in Swedish but not in Chinese populations. Scand J Gastroenterol 2007, 42:1332-1338.

34. Gao L, Nieters A, Brenner H: Meta-analysis: tumour invasion-related genetic polymorphisms and gastric cancer susceptibility. Aliment Pharmacol Ther 2008, 28:565-573.
35. Aggarwal BB, Shishodia S, Sandur SK, Pandey MK, Sethi G: Inflammation and cancer: how hot is the link? Biochem Pharmacol 2006, 72:1605-1621.

36. Yang J, Pan WH, Clawson GA, Richmond A: Systemic targeting inhibitor of kappaB kinase inhibits melanoma tumor growth. Cancer Res 2007, 67:3127-3134

37. Huang S, Robinson JB, Deguzman A, Bucana CD, Fidler IJ: Blockade of nuclear factor-kappaB signaling inhibits angiogenesis and tumorigenicity of human ovarian cancer cells by suppressing expression of vascular endothelial growth factor and interleukin 8. Cancer Res 2000, 60:5334-5339.

doi:10.1186/1471-230X-12-87

Cite this article as: Lu et al:: Association of an NFKB1 intron SNP (rs4648068) with gastric cancer patients in the Han Chinese population. BMC Gastroenterology 2012 12:87.

\section{Submit your next manuscript to BioMed Central and take full advantage of:}

- Convenient online submission

- Thorough peer review

- No space constraints or color figure charges

- Immediate publication on acceptance

- Inclusion in PubMed, CAS, Scopus and Google Scholar

- Research which is freely available for redistribution 